\title{
Application of mechano-chemical synthesis for protective coating on steel grinding media prior to ball milling of copper
}

\author{
INDRANIL LAHIRI* and K BALASUBRAMANIAN \\ Non-Ferrous Materials Technology Development Centre, P.O. Kanchanbagh, Hyderabad 500 058, India
}

MS received 16 October 2006; revised 12 March 2007

\begin{abstract}
One of the major sources of contamination during mechanical milling/alloying is from the surface erosion of the container and the grinding medium. This can either be prevented by using grinding medium and container of same material of the milled material or by adding a coating of the milled material on them. The paper describes the observations made during a mechano-chemical reaction, being used for coating the balls and vials in a planetary ball mill. Visual observation, XRD, optical micrography and EDS analysis were used to understand the progress of the reaction. Copper was successfully coated on the steel balls and vials. The method can easily be adopted in daily production purposes, prior to mechanical milling of a $\mathrm{Cu}$-based powder for prevention of Fe contamination.
\end{abstract}

Keywords. Mechanical milling; surface erosion; Fe contamination; Cu-based powder; mechano-chemical reaction; X-ray techniques.

\section{Introduction}

Surface erosion of the container and the grinding medium plays a major role in contamination during mechanical milling (Murty and Ranganathan 1998). This kind of contamination can be avoided by (i) using less energetic mills like vibratory mills (Koch 1991), (ii) reducing mill speed (Murty and Ranganathan 1998) or (iii) using grinding medium (balls during ball milling) and containers (vials) of the same material as that of the milled powder (Koch 1991; Murty and Ranganathan 1998; Suryanarayana 2001). The first two solutions lead to compromise with the process parameters. The third one, on the other hand, is not practically feasible in many systems. Contamination products in milled products are usually separated by a post-milling operation such as leaching. Proper selection of leaching parameters is very much essential to ensure that powder chemistry and morphology does not get affected. Moreover, the process parameters have to be chosen and optimized for each individual system. Taking into consideration the pros and cons of these various options, a pre-milling operation, such as development of a thin adherent coating of the same material of the milled powder, on the normal grinding media, seems to be the best solution to this problem. Benefits of using the normal grinding media as well as avoiding contamination from them can be achieved by using such coated balls and vials.

*Author for correspondence (indrani178@yahoo.com)
Balls and vials can be coated by various surface engineering techniques. Conventional practice is to coat the balls and the vials, using pure $\mathrm{Cu}$ powder, in pre-milling operation. However, this is a costly process due to the high raw material cost and hence, is not widely accepted by the industry. A cheaper method, however, can make this technique popular among industries. Utilization of mechanical milling itself to produce an in situ coating is simple and promising yet fast enough, and cost-effective method.

Mechano-chemical synthesis has long been used for displacement reactions, mainly for synthesis of different phases. Shen et al (1992) used mechanical alloying for a solid state red-ox reaction in the $\mathrm{Fe}-\mathrm{CuO}$ system. Similarly, mechanical alloying was used by Xi et al (1998) for studying a set of reactions in $\mathrm{Al}-\mathrm{CuO}$ system at different concentration levels. Many other systems are also tried successfully through mechano-chemical route (El-Eskandarany 1995). It was shown for $\mathrm{Fe}-\mathrm{CuO}$ system that the rate-controlling step changes from intrinsic ion diffusion to diffusion through short-circuit paths during milling (Forrester and Schaffer 1995). It was suggested in that study that the change in reaction rate is controlled by strain accumulation in the material during mechanical alloying. In the present study, the feasibility of engineering the surfaces of the balls and vials has been explored using mechano-chemical synthesis. Specifically, a coating of $\mathrm{Cu}$ is produced on the balls and vials, which would later be used for $\mathrm{Cu}-\mathrm{Cr}$ mechanical milling experiments. It may be noted that $\mathrm{Fe}$ contamination as high as $20.7 \%$ is reported in mechanical milling of $\mathrm{Cu}$ (Gaffet et al 1993). 


\section{Experimental}

The experiment was based on the following reaction:

$$
\mathrm{CuSO}_{4} \cdot 5 \mathrm{H}_{2} \mathrm{O}+\mathrm{Fe}+2 \mathrm{H}_{2} \mathrm{O}=\mathrm{FeSO}_{4} \cdot 7 \mathrm{H}_{2} \mathrm{O}+\mathrm{Cu} .
$$

This experiment was divided into two steps: one starting with only $10 \%$ of the stoichiometrically required water, but adding $10 \%$ of water after every $5 \mathrm{~h}$ of milling and the second one having $100 \%$ of the stoichiometrically required water from the beginning of milling itself. Only distilled water was used for this purpose.

For comparison purposes, an experiment as per the following reaction was also performed.

$$
\mathrm{CuCl}_{2} \cdot 2 \mathrm{H}_{2} \mathrm{O}+\mathrm{Fe}=\mathrm{FeCl}_{2} \cdot 2 \mathrm{H}_{2} \mathrm{O}+\mathrm{Cu} .
$$

Chemicals used in the experiments were of reagent grade. All the experiments were performed in a 'Fritsch Pulverisette 5' planetary ball mill. Five numbers of $25 \mathrm{~mm}$ diameter balls, totally weighing $\sim 315 \mathrm{~g}$ and a ball to powder ratio (BPR) of $8: 1$ were used for the experiments. The mill was constantly run at $200 \mathrm{rpm}$. The balls and vials were made of hardened steel. Reagent grade toluene was used as process control agent throughout the duration of milling operation. Fixing all these parameters ensures that effects of type of mill, size and weight of balls, ball to powder ratio, speed of the mill and process control agents will be same for all the experiments.

Visual inspection of the balls and vial surface was made after $5 \mathrm{~min}$ and at every hour up to $5 \mathrm{~h}$ and at every $5 \mathrm{~h}$ up to $50 \mathrm{~h}$. Samples were collected at some specified time intervals only, as mentioned in the next section. $\mathrm{XRD}$ of the powder samples was performed in a Philips XPert system.

\section{Results and discussion}

In the first step of the experiment, no coating was observed visually on the surface of the balls and vials till $30 \mathrm{~h}$. After $35 \mathrm{~h}$ of milling i.e. after addition of $70 \%$ of the required water, some reddish coating was observed on the balls and vial surfaces. XRD of the powder sample showed presence of $\mathrm{FeSO}_{4} \cdot 7 \mathrm{H}_{2} \mathrm{O}$ in the mixture, apart from $\mathrm{Cu}$ and unreacted $\mathrm{CuSO}_{4} \cdot 5 \mathrm{H}_{2} \mathrm{O}$ (figure 1(a)) indicating initiation of forward reaction. At this stage, $5 \mathrm{~g}(\sim 50 \%$, making total water content to $120 \%$ of stoichiometrically required amount) of water was added leading to faster reaction rate. As may be observed in the XRD pattern of the mixture, after $40 \mathrm{~h}$ (figure 1(b)) of milling, $\mathrm{FeSO}_{4} \cdot 7 \mathrm{H}_{2} \mathrm{O}$ was the main phase, while $\mathrm{CuSO}_{4} \cdot 5 \mathrm{H}_{2} \mathrm{O}$ and $\mathrm{Cu}$ turned out to be low in volume. As the reaction product contains $\mathrm{Cu}$, its volume fraction also should have been high. The only explanation of its less volume in such a closed reaction system can be its appearance in some other form. Reddish colour of the balls and vial surface indicates that copper was predominantly deposited on them and thus the reaction product has less copper in it. Continuing the milling operation up to $50 \mathrm{~h}$ did not produce any change in the nature of the reaction product and the coatings, indicating equilibrium between the reactants and the products.

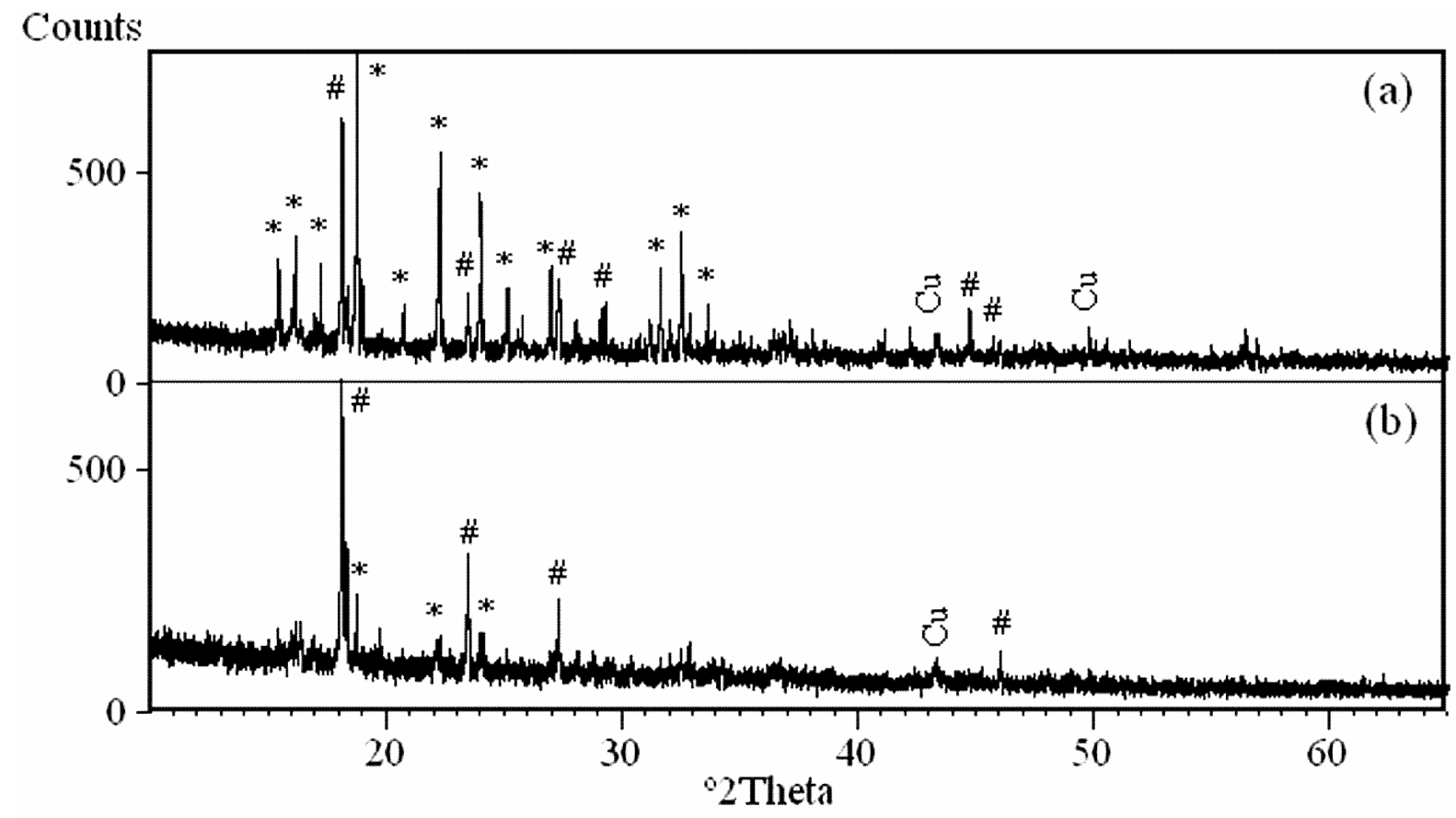

Figure 1. $\mathrm{XRD}$ pattern of the powder mixture during first stage of the experiment after (a) $35 \mathrm{~h}$ of milling showing peaks of $\mathrm{FeSO}_{4} \cdot 7 \mathrm{H}_{2} \mathrm{O}, \mathrm{CuSO}_{4} \cdot 5 \mathrm{H}_{2} \mathrm{O}$ and $\mathrm{Cu}$ and (b) $40 \mathrm{~h}$ of milling showing peaks of $\mathrm{FeSO}_{4} \cdot 7 \mathrm{H}_{2} \mathrm{O}, \mathrm{CuSO}_{4} \cdot 5 \mathrm{H}_{2} \mathrm{O}$ and $\mathrm{Cu}\left[*\right.$ denotes $\mathrm{CuSO}_{4} \cdot 5 \mathrm{H}_{2} \mathrm{O}$ and \# denotes $\mathrm{FeSO}_{4} \cdot 7 \mathrm{H}_{2} \mathrm{O}$ in the figures]. 


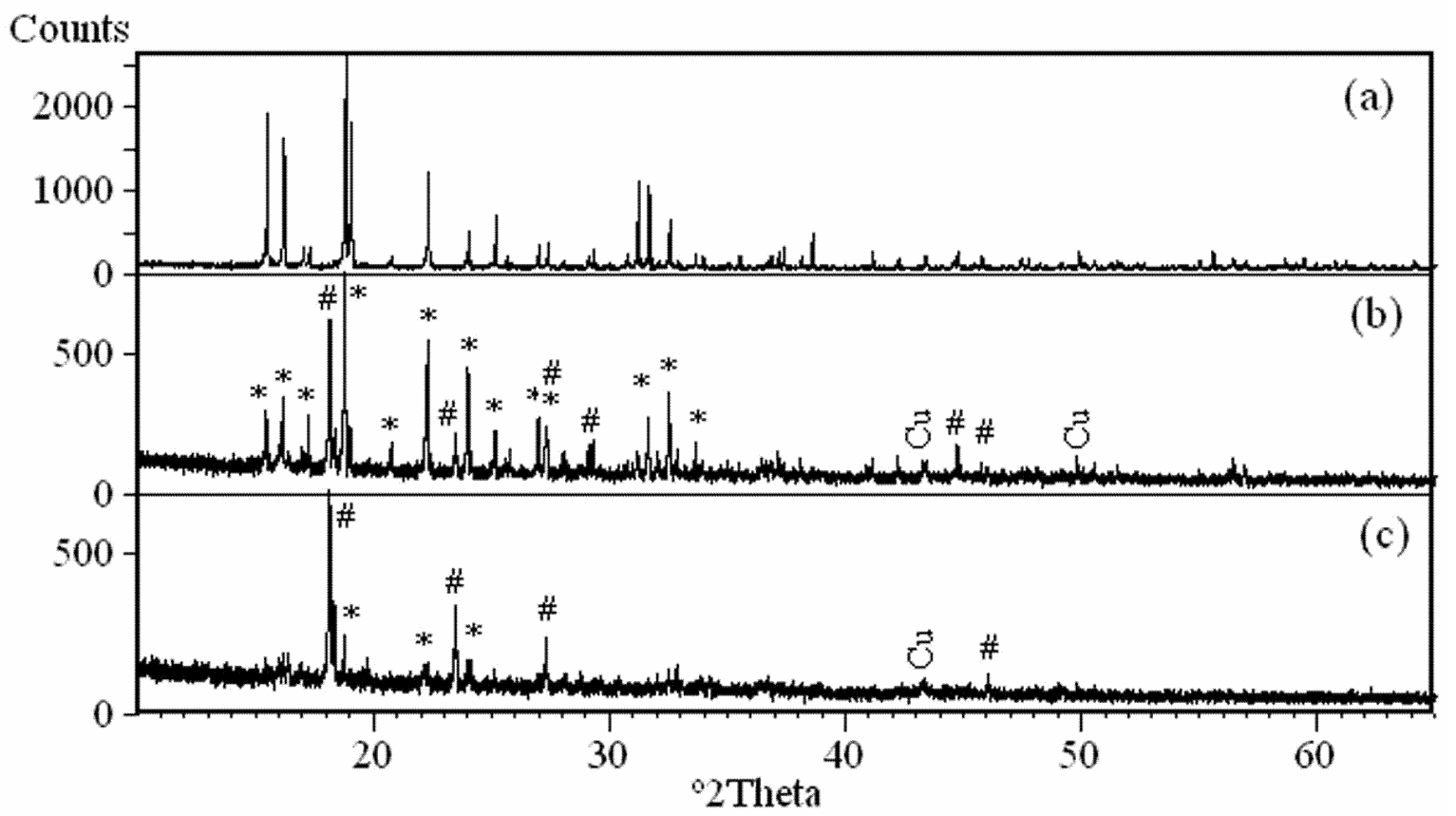

Figure 2. XRD pattern of the powder mixture during second stage of the experiment after (a) 5 min of milling showing peaks of $\mathrm{CuSO}_{4} \cdot 5 \mathrm{H}_{2} \mathrm{O}$ only, (b) $1 \mathrm{~h}$ of milling showing peaks of $\mathrm{FeSO}_{4} \cdot 7 \mathrm{H}_{2} \mathrm{O}, \mathrm{CuSO}_{4} \cdot 5 \mathrm{H}_{2} \mathrm{O}$ and $\mathrm{Cu}$ and (c) $4 \mathrm{~h}$ of milling showing peaks of $\mathrm{FeSO}_{4} \cdot 7 \mathrm{H}_{2} \mathrm{O}, \mathrm{CuSO}_{4} \cdot 5 \mathrm{H}_{2} \mathrm{O}$ and $\mathrm{Cu}\left[{ }^{*}\right.$ denotes $\mathrm{CuSO}_{4} \cdot 5 \mathrm{H}_{2} \mathrm{O}$ and \# denotes $\mathrm{FeSO}_{4} \cdot 7 \mathrm{H}_{2} \mathrm{O}$ in the figures].

Due to the slow reaction rates up to $35 \mathrm{~h}$ followed by enhanced rate after addition of extra amount of water, it can be concluded that presence of extra amount of water increases the reaction rate such that the forward reaction is favoured. Hence, it was decided that the next experiment would be started with $100 \%$ of the stoichiometrically required water.

After $5 \mathrm{~min}$ of milling, in the next step of the experiment, colour of the powder was typical bluish of copper sulphate. No reddish coating of copper was observed on the balls or vial surfaces. XRD of the powder mixture also confirmed that the reaction had not yet started (figure 2(a)). After $1 \mathrm{~h}$ of milling, a greenish precipitate was found to be formed. XRD of the mixture showed presence of $\mathrm{CuSO}_{4} \cdot 5 \mathrm{H}_{2} \mathrm{O}, \mathrm{FeSO}_{4} \cdot 7 \mathrm{H}_{2} \mathrm{O}$ and $\mathrm{Cu}$ (figure 2(b)). Balls and vial surfaces started looking reddish. After $4 \mathrm{~h}$ of milling, it was observed that the balls and vials had become reddish in appearance and the powder mixture showed presence of mainly $\mathrm{FeSO}_{4} \cdot 7 \mathrm{H}_{2} \mathrm{O}$ and little amounts of $\mathrm{Cu}$ and $\mathrm{CuSO}_{4} \cdot 5 \mathrm{H}_{2} \mathrm{O}$ (figure 2(c)). Continuing the milling operation till $20 \mathrm{~h}$ did not change either the powder chemistry or the appearance of the balls. The product mixture did not show presence of high amount of $\mathrm{Cu}$, as expected to be produced from the reaction. Reddish appearance of the balls and vials indicates that most of the copper, produced from the reaction, was used for coating them.

This route of coating the balls was fast (reaction completed within $4 \mathrm{~h}$ ) and the coating thus produced was also found to be adherent. A cross-section of the ball was mounted and polished to measure the $\mathrm{Cu}$-coating thick- ness by image analysis. Figure 3 shows an optical micrograph of the cross-section of the balls. The $\mathrm{Cu}$ layer can be clearly observed on the ball surface. The coating was found to be quite uniform and varied in thickness between 6 and $8 \mu \mathrm{m}$ only. The coating layer being so thin could not produce an XRD/XRF response to verify the presence of phases/elements in the coating. However, a chemical spot test confirmed the presence of $\mathrm{Cu}$ on the ball surface. Further, the ball was subjected to EDS analysis. The resulting pattern is shown in figure 4 . Presence of $\mathrm{Cu}$ peaks in the pattern clearly establishes the claim of $\mathrm{Cu}$ coating on the balls. However, the main peaks in the pattern are of $\mathrm{Fe}$ and $\mathrm{Cr}$, which comes from the high- $\mathrm{Cr}$ steel balls.

Later, these balls and vials were used in $\mathrm{Cu}-10 \% \mathrm{Cr}$ milling operation for $550 \mathrm{~h}$. The balls were still having reddish coating of copper on their surfaces. Crosssections of balls, collected after different time intervals, were subjected to metallography and image analysis to measure the coating thickness. Figure 5 shows the plot between $\mathrm{Cu}$ coating thickness and milling time. At the beginning of milling, the balls had a $4 \mu \mathrm{m}$ thick $\mathrm{Cu}$ coating (generated from the pre-milling operation). With increasing milling time, the coating thickness increases and ultimately stabilizes in the range $9-10 \mu \mathrm{m}$. After $50 \mathrm{~h}$ of milling, an equilibrium between coating and wear is established, which stabilizes the coating thickness. Fe contamination to $\mathrm{Cu}-\mathrm{Cr}$ powder mixture at the end of $550 \mathrm{~h}$ of milling is only $0 \cdot 2 \%$. In the absence of pre-coated balls, nearly $10 \% \mathrm{Fe}$ was observed to be present in the milled powder of $\mathrm{Cu}-25 \% \mathrm{Cr}$. 


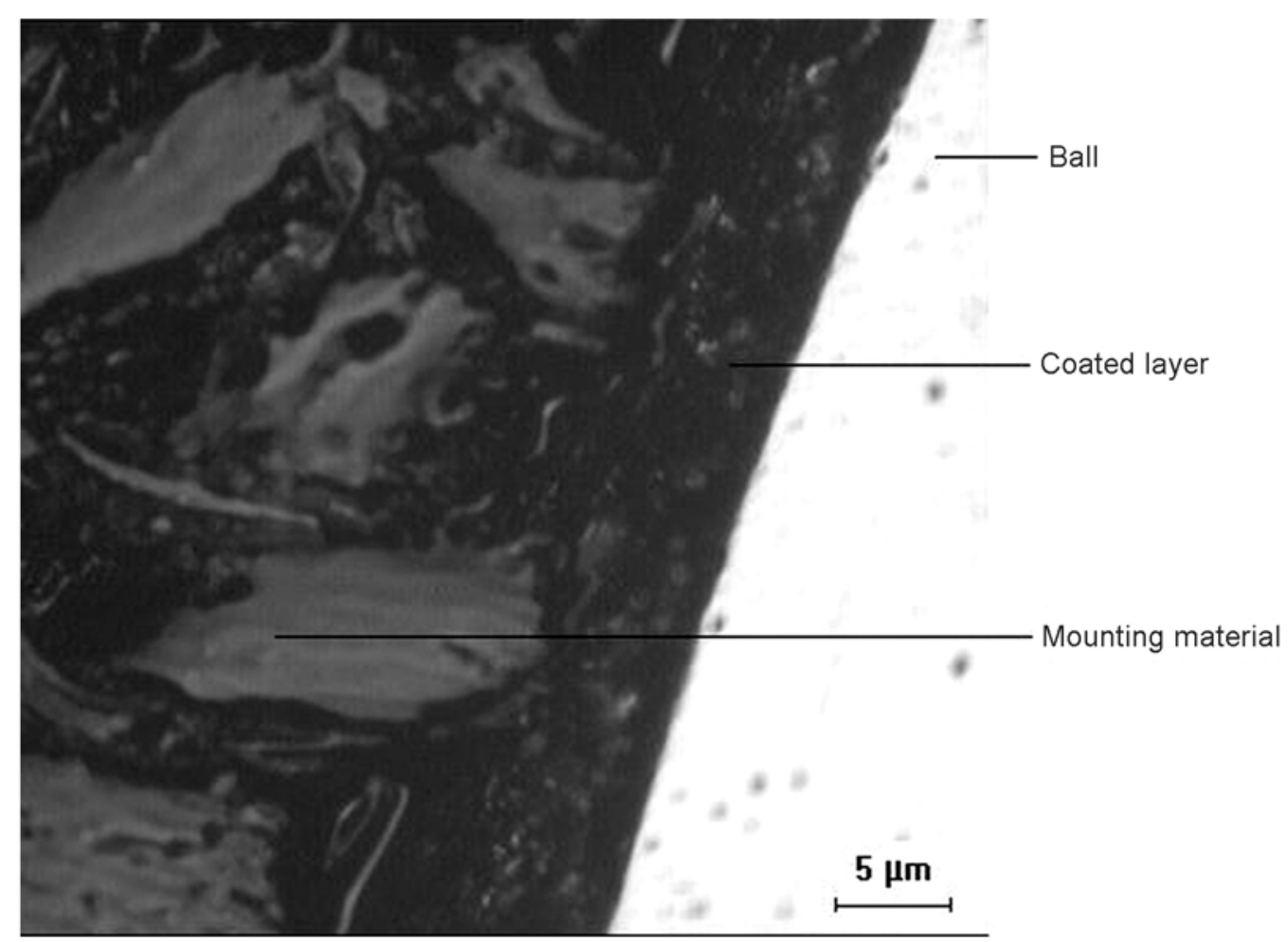

Figure 3. Optical micrograph of the cross-section of a ball showing $\mathrm{Cu}$ layer on it.

\section{Full scale counts: 873}

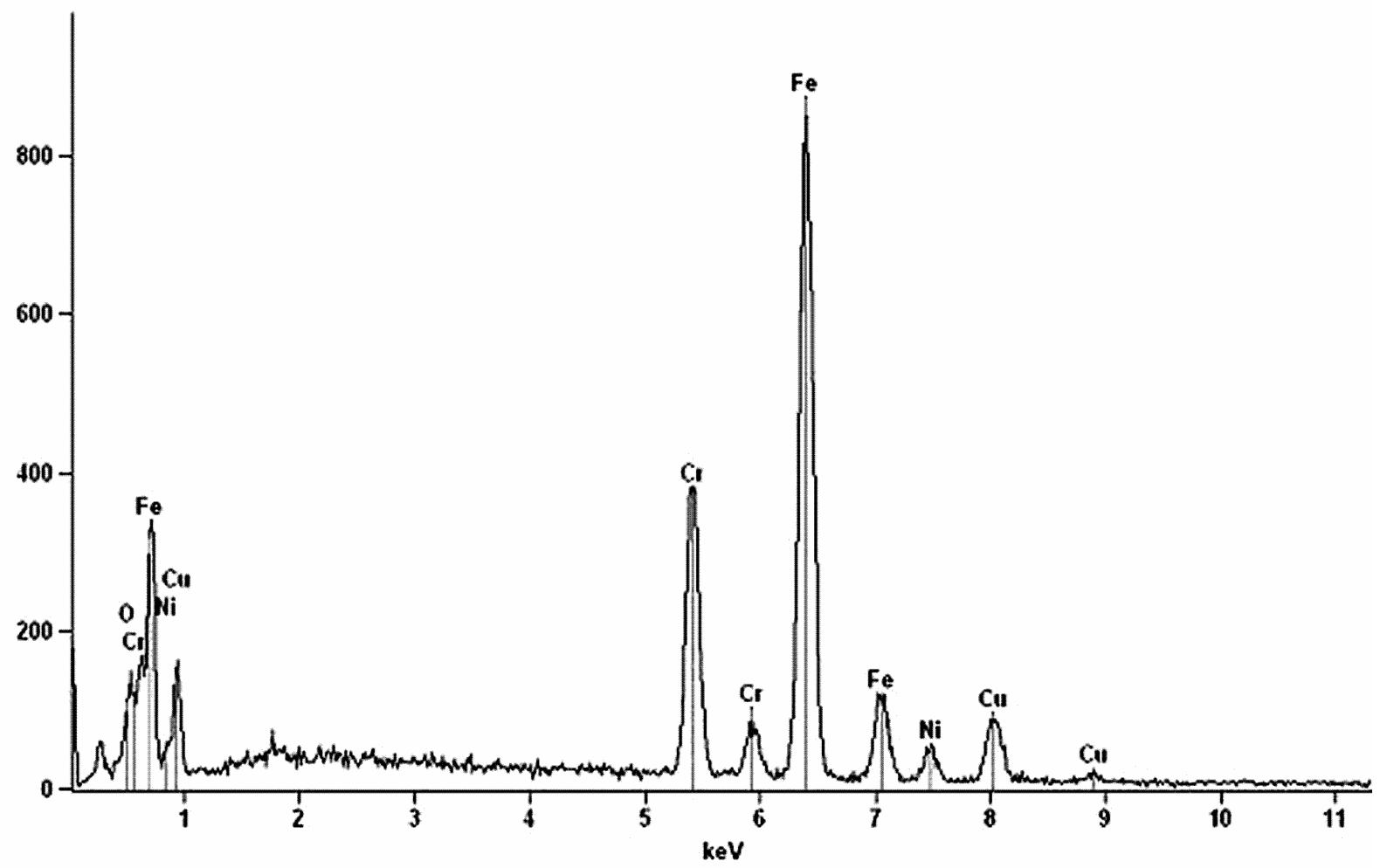

Figure 4. EDS pattern of the coated ball showing presence of $\mathrm{Cu}$. 


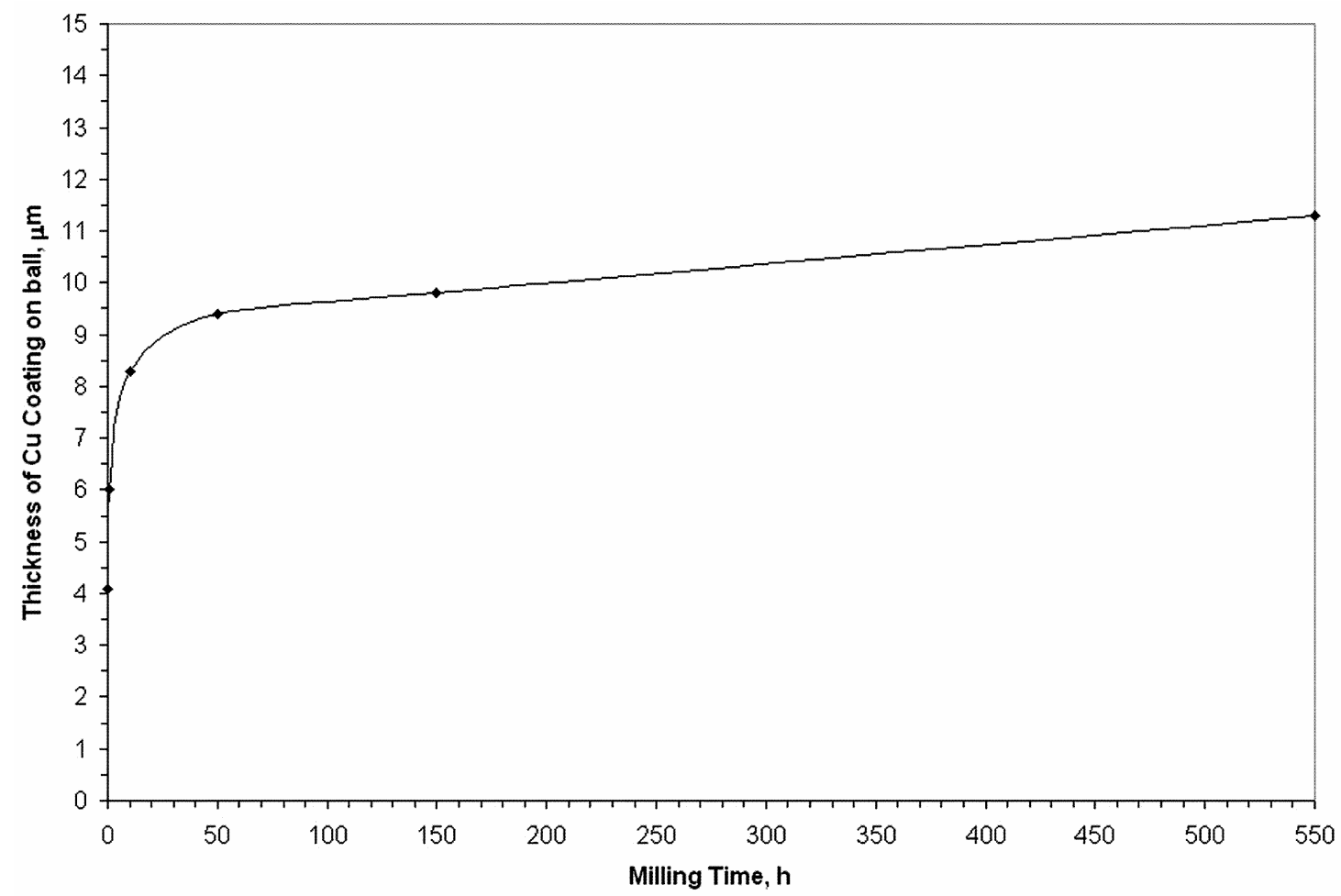

Figure 5. A plot between $\mathrm{Cu}$ coating thickness and milling time. The coating thickness is stabilized after $50 \mathrm{~h}$ of milling.

The conventional route of coating (using pure $\mathrm{Cu}$ powder) is not cost-effective, due to higher price of pure $\mathrm{Cu}$ powder as compared to pure grade of $\mathrm{CuSO}_{4} \cdot 5 \mathrm{H}_{2} \mathrm{O}$. This proves the efficacy of the mechano-chemical method, followed in the present study, in producing protective coating on the grinding media. Moreover, the method is simple to use, cost-effective, fast enough and does not require any other instrumental set-up. The ingredients used are also readily available. Therefore, this route can easily be followed during mechanical alloying of copper base powders using steel balls and vials for prevention of contamination from steel grinding media.

Theoretically, many salts and displacement reactions can be used to coat $\mathrm{Cu}$ on the steel balls. However, it is important to select proper reaction system. For comparison purpose, same type of experiment was tried with $\mathrm{CuCl}_{2} \cdot 2 \mathrm{H}_{2} \mathrm{O}$ instead of hydrated copper sulphate. The reaction was so vigorous that within $1 \mathrm{~h}$ of milling the balls and vial surface were heavily eroded. Though an adhesive coating of reddish $\mathrm{Cu}$ was found to be formed at different positions of vial, high erosion rate of steel balls and vials rendered this option not useful.

\section{Conclusions}

A mixture of $\mathrm{CuSO}_{4} \cdot 5 \mathrm{H}_{2} \mathrm{O}$ and stoichiometrically required amount of water was found to form an adherent $\mathrm{Cu}$ coat- ing on the surface of steel balls and vials within $4 \mathrm{~h}$ of mechanical milling. The coating could not be removed even after $550 \mathrm{~h}$ of milling with $\mathrm{Cu}-10 \% \mathrm{Cr}$ powder and $\mathrm{Fe}$ contamination at the end of the milling was found to be only $0 \cdot 2 \%$. Moreover, the process is very cheap, easy to operate, fast enough yet under control and it does not require any other method or set up and costly reagents. Thus, it can be successfully used in daily applications of $\mathrm{Cu}$-based milling using steel balls and containers.

\section{References}

El-Eskandarany M Sherif 1995 Mater. Trans. JIM 36182

Forrester J S and Schaffer G B 1995 Met. Mater. Trans. A26 725

Gaffet E, Harmelin M and Faudot F 1993 J. Alloys \& Compounds 19423

Koch C C 1991 in Processing of metals and alloys, materials science and technology - a comprehensive treatment (ed.) R W Cahn (Weinheim: VCH) 15 p. 193

Murty B S and Ranganathan S 1998 Int. Mater. Rev. 43101

Shen T D, Wang K Y, Wang J T and Quan M X 1992 Mater. Sci. Engg. A151 189

Suryanarayana C 2001 Prog. Mater. Sci. 461

Xi Shengqi, Qu Xiaoyan, Ma Mingliang, Zhou Jingen, Zheng Xiulin and Wang Xiaotian 1998 J. Alloys \& Compounds 268 211 